Research article

\title{
Timed sequential chemotherapy with concomitant Granulocyte Colony-Stimulating Factor for high-risk acute myelogenous leukemia: a single arm clinical trial Xing-Yue He ${ }^{1}$, Paul Elson², Brad Pohlman ${ }^{1}$, Alan Lichtin ${ }^{1}$, Mohamad Hussein ${ }^{1}$, Steve Andresen ${ }^{1}$ and Matt Kalaycio*1
}

Address: ${ }^{1}$ Department of Hematology and Medical Oncology, Cleveland Clinic Foundation, Cleveland, Ohio USA and ${ }^{2}$ Department of Biostatistics, The Cleveland Clinic Foundation, Cleveland, Ohio USA

E-mail: Xing-Yue He - hes@ccf.org; Paul Elson - elsonp@ccf.org; Brad Pohlman - pohlmab@ccf.org; Alan Lichtin - lichtia@ccf.org; Mohamad Hussein - hussem@ccf.org; Steve Andresen - andress@ccf.org; Matt Kalaycio* - kalaycm@ccf.org

*Corresponding author

Published: 9 May 2002

BMC Cancer 2002, 2:12
Received: 22 February 2002

Accepted: 9 May 2002

This article is available from: http://www.biomedcentral.com/I47I-2407/2/12

(C) $2002 \mathrm{He}$ et al; licensee BioMed Central Ltd. This article is published in Open Access: verbatim copying and redistribution of this article are permitted in all media for any non-commercial purpose, provided this notice is preserved along with the article's original URL.

\begin{abstract}
Background: The timed-sequential chemotherapy regimen consisting of etoposide, mitoxantrone and cytarabine (EMA) is an effective therapy for relapsed or refractory acute myelogenous leukemia (AML). We postulated that granulocyte colony-stimulating factor (G-CSF) might enhance the cytotoxicity of EMA by increasing the proportion of leukemic blasts in S-phase. We added G-CSF to EMA (EMA-G) for therapy of advanced high-risk AML patients.

Methods: High-risk AML was defined as refractory, relapsed or secondary to either an antecedent hematologic disorder or exposure to cytotoxic agents. The patients were treated with one course of EMA-G consisting of mitoxantrone and cytarabine on days $1-3$, and etoposide and cytarabine on days 8-10. G-CSF was started on day 4 and continued until absolute neutrophil count recovered.

Results: Thirty patients were enrolled. The median age was $5 \mathrm{I}$ years (range, 25-75). Seventeen $(61 \%)$ patients had unfavorable cytogenetic karyotypes. Twenty $(69 \%)$ patients had secondary AML. Ten (34\%) had relapsed disease. Four (14\%) had refractory AML. Three (10\%) patients died from febrile neutropenia and sepsis. Major non-hematologic toxicity included hyperbilirubimenia, renal insufficiency, mucositis, diarrhea, nausea and vomiting, skin rash. A complete remission was achieved in $13(46 \%)$ patients. Median overall survival was 9 months (range, 0.5-66). Median relapse-free survival (RFS) for those who had a CR was 3 months (range, 0.5-63) with RFS censored at the time of allogeneic bone marrow transplantation or peripheral stem cell transplantation for 6 of the patients.
\end{abstract}

Conclusions: EMA-G is a safe and efficacious option for induction chemotherapy in advanced, high-risk AML patients. The activity of EMA may be increased if applied in patients with less advanced disease. 


\section{Background}

The promise of improved outcome with the use of hematopoietic growth factors in the treatment of acute myelogenous leukemia (AML) has yet to be realized. In several prospective trials, patients were randomized to either a hematopoietic growth factor or a placebo after induction chemotherapy in an attempt to accelerate neutrophil recovery and improve outcome. These studies consistently show accelerated neutrophil recovery without an increase in leukemic relapse in patients treated with either granulocyte colony stimulating factor (G-CSF) or granulocytemacrophage colony stimulating factor (GM-CSF). [1-4] Unfortunately these studies have failed to consistently show a benefit in terms of remission and survival when administered in such an adjuvant fashion. [5,6]

The hematopoietic growth factors have also been studied for their therapeutic benefits when given before chemotherapy. Both G-CSF and GM-CSF recruit quiescent leukemic blasts into cell cycle thus rendering them more susceptible to the S-phase specific cytotoxicity of cytarabine. [7-13] Several studies suggest a potential therapeutic benefit from administering hematopoietic growth factors before starting cytarabine-based chemotherapy. [14-19] However, the results of larger randomized trials have been disappointing. [20-23] Not only have remission and survival rates not been increased but the direct effect of growth factors on the untreated leukemia has led to severe toxic reactions and death. [24-26]

Chemotherapy also recruits quiescent leukemic blasts into cell cycle. Burke and colleagues demonstrated in an in vitro model that following an initial cycle of chemotherapy "humoral factors" are generated which are capable of recruiting quiescent leukemic blasts into S-phase. [27] The maximal recruitment occurred about 4 to 6 days after chemotherapy was administered. To apply these observations clinically, patients were first treated with cytarabine and daunorubicin. This initial cycle of chemotherapy was then followed by either a second course of cytarabine on day 10 or AMSA on days 8-10. This "timed sequential therapy" achieved a complete remission rate of $88 \%$ in de novo and $70 \%$ in secondary AML. [28] Timed sequential therapy has been employed in relapsed and de novo acute leukemia and achieves complete remission rates comparable to those achieved with other salvage chemotherapeutic regimens. [29,30]

The combination of timed sequential chemotherapy and hematopoietic growth factors allows for an initial cytoreductive course of chemotherapy before starting growth factors. The growth factor could then work with the other "humoral factors" generated by chemotherapy to maximize recruitment of leukemic blasts into cell cycle. Few studies have tested this approach. We report the results of a clinical trial assessing the potential benefit of adding GCSF to a proven timed sequential chemotherapeutic regimen.

\section{Materials and Methods Patients}

All patients had AML defined according to the standard French-American-British (FAB) cytologic and cytochemical criteria [47]. Patients were considered to have goodrisk cytogenetics if their karyotype revealed either $t(8 ; 21)$, inv $(16), \mathrm{t}(16 ; 16)$ or $\mathrm{t}(15: 17)$. A normal karyotype defined intermediate-risk cytogenetics. All other clonal abnormalities were considered poor-risk. Patients were eligible for this protocol if their leukemia was: 1) refractory to previous induction chemotherapy, 2) in first or subsequent relapse after initial complete remission following induction chemotherapy, 3) secondary to transformation from an antecedent hematologic disorder, or 4) secondary to previous exposure to cytotoxic agents. All patients were over 18 years of age. Only patients with a performance status of 2 or less and no organ failure [less than grade 2 according to the World Health Organization (WHO) grading system] could enter the study, except if organ failure was related to the leukemia itself. Patients with leukemic meningitis were excluded. All patients gave signed informed consent and were treated on clinical protocols approved by the Cleveland Clinic Foundation's Institutional Review Board.

\section{EMA-G Regimen}

The EMA regimen contains etoposide, mitoxantrone and cytarabine administered in a timed-sequential fashion. [32] We added G-CSF to the EMA regimen, thus EMA-G. EMA-G consists of mitoxantrone $12 \mathrm{mg} / \mathrm{m}^{2}$ per day intravenous (IV) bolus for 3 days (day 1 to 3 ) with cytarabine $500 \mathrm{mg} / \mathrm{m}^{2}$ per day IV continuous infusion (CI) for 72 hours (day 1 to 3 ). Etoposide $200 \mathrm{mg} / \mathrm{m}^{2}$ per day IVCI for 72 hours and cytarabine $500 \mathrm{mg} / \mathrm{m}^{2}$ per day IVCI for 72 hours were administered on day 8 to 10 . G-CSF $5 \mathrm{mg} / \mathrm{kg}$ per day subcutaneouly was started on day 4 and continued until the absolute neutrophil count (ANC) rose above $0.5 \times 10^{\%} / \mathrm{L}$ for two consecutive days (Fig. 1). Only one course of EMA-G induction was given. Post remission therapy included chemotherapy, allogeneic bone marrow transplantation (BMT) or peripheral stem cell transplantation (PSCT) at the treating physician's discretion and availability of a transplant donor.

All patients were cared for in semi-private rooms supplied with HEPA filters on a regular oncology unit. All patients received standard supportive care including blood component support for severe cytopenias as previously described.[31] Acyclovir $250 \mathrm{mg} / \mathrm{m}^{2}$ per day IV or $400-800$ mg PO bid, allopurinol $300 \mathrm{mg}$ PO qd and fluconazole $400 \mathrm{mg}$ PO qd were administered prophylactically. 


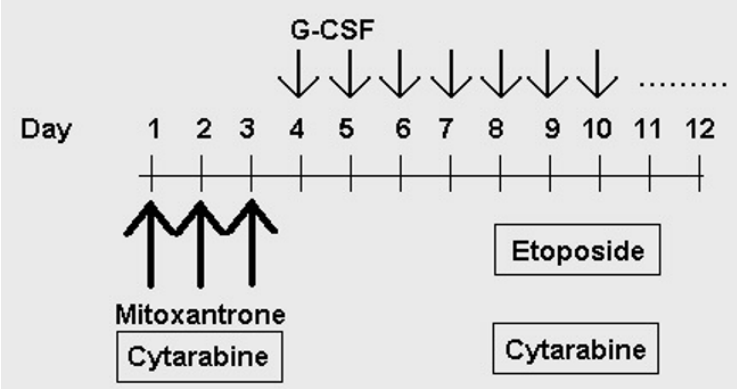

Figure I

Schema of EMA-G regimen.

\section{Evaluation of Therapy}

Bone marrow aspirates and biopsies were obtained on day 8 of chemotherapy and then at the discretion of the treating physicians. When a bone marrow aspirate or biopsy obtained on or after Day 14 contained 5\% or more blast cells, G-CSF was stopped.

Complete remission (CR) was achieved when the following parameters were met: 1) bone marrow was normocellular, containing $<5 \%$ blasts, $>15 \%$ erythroid cells, and $>25 \%$ normal granulocytes; 2 ) peripheral blood had neutrophils $>1.5 \times 10^{9} / \mathrm{L}$, hemoglobin $>11 \mathrm{gm} / \mathrm{dl}$, and platelets $\left.>1 \times 10^{11} / \mathrm{L} ; 3\right)$ no evidence of extramedullary leukemia, and 4) all of the above fulfilled for at least 4 weeks. Nonresponse to EMA-G induction was defined as the absence of CR after one course of induction therapy. Relapse was defined by the appearance of circulating blasts or bone marrow blasts $>5 \%$ in a patient previously in complete remission.

\section{Evaluation of Toxicity}

Severity of treatment-related toxicity was graded according to the WHO criteria (World Health Organization Handbook for Reporting Results of Cancer Treatment, 1979.)

\section{Statistical Analysis}

The method of Kaplan and Meier was used to analyze overall survival, relapse-free survival, time to neutrophil recovery and time to platelet recovery. Exact $95 \%$ confidence intervals (CI) based on the binomial distribution were calculated for proportions such as the complete response rate.
Table I: Characteristics of 29 patients with AML treated with EMA-G.

\begin{tabular}{lc}
\hline Patients & 29 \\
Median Age (years) & 51 \\
Range & $(25-75)$ \\
Male: Female & $16: 13$ \\
Karyotype $(\mathrm{n}=28)$ & 1 \\
$\quad$ Favorable & 10 \\
$\quad$ Intermediate & 17 \\
$\quad$ Unfavorable & \\
Etiology of AML & 9 \\
$\quad$ Primary & 20 \\
$\quad$ Secondary & \\
Stage of the disease & 15 \\
$\quad$ Untreated (all secondary) & 4 \\
$\quad$ Refractory & 5 \\
Relapsed < I year & 5 \\
Relapsed > I year &
\end{tabular}

\section{Results \\ Patients}

From August 1994 to November 1996, 30 patients were enrolled onto this study. One patient received high-dose cytarabine instead of EMA-G for induction therapy after enrollment and was therefore excluded from further analysis. Thus, 29 patients received EMA-G induction therapy and are evaluable for treatment-related toxicity. Only 28 patients are evaluable for induction response since $1 \mathrm{pa}-$ tient was lost to follow-up shortly after receiving induction therapy (no evidence of persisting leukemia by the post-induction bone marrow biopsy). The characteristics of the evaluable patients are listed in Table 1. Twentyeight patients had cytogenetic studies of bone marrow aspirates. Most patients (61\%) had unfavorable karyotypes. The majority of patients $(69 \%)$ had secondary AML transformed from either MDS $(n=10)$, CML $(n=5)$ or other myeloproliferative diseases $(n=4)$, or secondary to cytotoxic agents $(n=1)$. Overall, 15 patients with secondary, but untreated, AML were enrolled. Four patients were enrolled with AML refractory to previous induction therapy, and 10 were enrolled with relapsed AML.

\section{Recovery of neutrophil and platelet counts}

The median time from the start of chemotherapy to recovery of an absolute neutrophil count exceeding $0.5 \times 10^{9} / \mathrm{L}$ was 30 days (range, 19 to 47 days). Three patients died of febrile neutropenia and sepsis during induction therapy. The median duration of platelet transfusion dependence was 30 days (range, 22 to 48 days).

\section{Efficacy of Therapy}

Twenty-eight patients are evaluable for treatment response. Thirteen patients $(46 \%, 95 \%$ CI $27 \%-66 \%)$ 
achieved a complete remission. Seven of those 13 patients with CR had secondary leukemia. Twelve patients (43\%) failed to achieve CR following induction treatment. One of the non-responders had no evidence of leukemia after induction treatment and proceeded to bone marrow transplant before meeting all of the criteria for complete remission. Three patients (10\%) died during induction treatment.

Of the 13 patients who achieved CR, 6 patients received further consolidation chemotherapy ( 3 with high dose cytarabine, and 3 with intermediate dose cytarabine combined with daunorubicin, etoposide, or interleukin-2), and 6 patients received either allogeneic BMT or allogeneic PSCT. One patient relapsed before any post-remission therapy was given. Of the 13 patients who did not achieve CR, 1 received salvage chemotherapy, 2 received allogeneic BMT, and 10 died due to rapid disease progression.

\section{Survival}

The median overall survival (OS) for all evaluable patients is 9 months (range, 0.5-66 months). Median relapse free survival (RFS) for those who achieved CR is 3 months (range, 0.5-63 months) with 6 patients censored at allogeneic BMT or PSCT. At five-years of follow-up, 3 patients (11\%) were still alive. Two of them were in CR, one of whom had allogeneic BMT and the other had high dose cytarabine as post-remission therapy. The third patient is alive with recurrent leukemia.

\section{Treatment-related Toxicity}

All patients experienced fever in the setting of severe neutropenia. Fifteen (15\%) patients had documented infections. Three patients $(10 \%)$ died from febrile neutropenia and sepsis. Other WHO grades III-IV toxicity included mucositis $(17 \%)$, diarrhea $(17 \%)$, skin rash $(14 \%)$, nausea and vomiting (14\%), bleeding (3\%). Ten (34\%) patients had reversible hyperbilirubinemia and $5(17 \%)$ had WHO grades III-IV renal insufficiency. Three $(10 \%)$ patients experienced severe neurological toxicity ( 1 with seizure, 2 with severe vertigo) but those complications resolved shortly after the completion of induction therapy. GCSF was stopped in 1 patient due to persisting peripheral blasts. When G-CSF was discontinued the peripheral blasts cleared and the patient achieved a complete remission.

\section{Discussion}

Hematopoietic growth factors clearly increase the cytotoxicity of cytarabine to leukemia cells in vitro. [33] Clinically, however, they fail to increase remission rates when started from 24 to 48 hours before any chemotherapy. [20-23] Potential explanations for the failure of growth factors to improve results when administered in this fash- ion may reflect either their adverse effect on a large leukemic burden or the necessary delay to the onset of chemotherapy. [34] In our study we started growth factors after the initial leukemic burden was reduced and then optimized the timing of a second course of chemotherapy to take advantage of known leukemic blast cell-cycle kinetics. [27] Our results are comparable to those achieved with other salvage chemotherapeutic regimens that employ high-dose cytarabine. [35-39]

Rather than use a standard high-dose cytarabine regimen we employed the EMA chemotherapy protocol devised by Archimbaud and colleagues. [40] This regimen is effective in patients with relapsed and refractory AML with a reported CR rate of $60 \%$. In addition EMA avoids the cerebellar neurotoxicity of high-dose cytarabine. Recognizing the potential value of hematopoietic growth factors, Archimbaud and colleagues added GM-CSF to the EMA regimen beginning on Day 4 of treatment. Unlike the current report, however, GM-CSF was discontinued on Day 10 of treatment. Unfortunately the addition of GM-CSF did not increase the CR rate when it was compared to placebo in a prospective randomized study in patients with relapsed and refractory AML. [41] The results with EMA and EMA plus GM-CSF are compared with our own results in Table 2.

Clearly the patient population in our study was different than the population studied in the other two studies employing the EMA regimen. Our population is older and a majority of our patients had secondary AML. These two characteristics are among the most predictive of a poor outcome. Although 15 of our patients were untreated at the time of study enrollment all 15 had secondary AML and 5 of them had CML in blast crisis unresponsive to hydroxyurea therapy. The poor-risk features of our patient population probably explain our relatively low $\mathrm{CR}$ rate compared to other EMA studies but also confirm the efficacy of our treatment protocol since remissions would only be expected in $40-50 \%$ of untreated patients with secondary AML receiving initial induction chemotherapy. [42-44]

Our study did not demonstrate a significant advantage to the addition of G-CSF to the EMA regimen. Potential reasons include the possibility that G-CSF failed to increase the population of leukemic stem cells in S-phase over that achieved with chemotherapy alone. Alternatively recruitment of blasts into S-phase may not increase cytotoxicity to a clinically significant degree. Finally even if S-phase increases cytotoxicity and G-CSF is effective in increasing the proportion of blasts in S-phase these effects may not be sufficient for patients with advanced leukemia. In the few studies exploring the role of timed-sequential chemotherapy as primary treatment for de novo untreated AML results 
Table 2: Comparison of three clinical trials of EMA with and without the use of hematopoietic growth factors.

\begin{tabular}{|c|c|c|c|c|}
\hline & $\mathrm{EMA}[40]$ & EMA-Placebo[4I] & EMA-GM[4I] & EMA-G \\
\hline Patients & 133 & 97 & 95 & 29 \\
\hline Median Age & 43 (mean) & 46 & 47 & 51 \\
\hline \multicolumn{5}{|l|}{ Status of AML } \\
\hline Refractory or relapsed $<1 \mathrm{yr}$ & 124 (93\%) & $61(64 \%)^{*}$ & $59(61 \%)^{*}$ & II (38\%) \\
\hline Relapsed $>1$ yr & $9(7 \%)$ & $36(36 \%)$ & $36(38 \%)$ & $3(10 \%)$ \\
\hline Secondary AML & $16(12 \%)$ & $16(16 \%)$ & $13(14 \%)$ & $20(69 \%)$ \\
\hline ANC $>0.5 \times 109 / L$ & 31 days & 37 & 38 & 30 \\
\hline CR Rate & $60 \%$ & $59 \%$ & $65 \%$ & $46 \%$ \\
\hline Toxic Death & $11 \%$ & $8 \%$ & $5 \%$ & $10 \%$ \\
\hline
\end{tabular}

* = Refractory AML plus Relapse AML within 6 months ANC = Time to recover a sustained absolute neutrophil count CR $=$ Complete Remission

have been more encouraging with high remission rates and prolonged survival. [45,46]

An initial concern with EMA-G was the effect the concurrent administration of G-CSF and chemotherapy might have on bone marrow recovery. However, the concern was unfounded since the median time to neutrophil and platelet recovery is not different than that noted with EMA (Table 2). This observation suggests that G-CSF may be administered concurrently with chemotherapy without an increase in toxicity to normal residual bone marrow. Other studies utilizing hematopoietic growth factors administered before and concurrently with chemotherapy also demonstrate no adverse effect on bone marrow recovery. [20-22]

\section{Conclusions}

The treatment of advanced high-risk AML patients remains challenging. The use of EMA-G in the current study failed to demonstrate a better CR rate than published data of EMA alone or EMA with GM-CSF (EMA-GM). However, the $46 \%$ CR rate achieved in our cohort of patients with a higher proportion of secondary AML and older median age suggests that the EMA-G regimen deserves further study in a population of patients with less advanced disease.

\section{Competing interests}

None declared

\section{Author's Contributions}

$\mathrm{X}$-YH collected and compiled the data and reviewed the manuscript with MK. PE participated in the design of the study, performed the statistical analysis and wrote the statistical section. $\mathrm{MH}, \mathrm{AL}, \mathrm{BP}$, and SA conducted the study, contributed patients, and commented on the data analysis and manuscript. MK conceived of the study, reviewed the data collection and analytical processes, and wrote the body of the manuscript. All authors read and approved the final manuscript.

\section{Abbreviations}

AML, acute myelogenous leukemia. G-CSF, granulocyte colony-stimulating Factor. GM-CSF, granulocyte-macrophage colony-stimulating Factor. EMA, etoposide, mitoxantrone and cytarabine. EMA-G, EMA and G-CSF.

\section{Acknowledgments}

We thank the nurses and staff of $\mathrm{H} 7 \mathrm{I}$ without whose aid we could not perfom our work.

\section{References}

I. Rowe JM, Andersen JW, Mazza JJ, Bennett JM, Paietta E, Hayes FA Oette D, Cassileth PA, Stadtmauer EA, Wiernik PH: A randomized placebo-controlled phase III study of granulocyte-macrophage colony-stimulating factor in adult patients ( $>55$ to 70 years of age) with acute myelogenous leukemia: A study of the Eastern Cooperative Oncology Group (El490). Blood 1995, 86(2):457-462

2. Dombret H, Chastang C, Fenaux P, Reiffers J, Bordessoule D, Bouabdallah R, Mandelli F, Ferrant A, Auzanneau G, Tilly H: A controlled study of recombinant human granulocyte colony-stimulating factor in elderly patients after treatment for acute myelogenous leukemia. AML Cooperative Study Group [see comments]. New Engl J Med 1995, 332(25):1678-I683

3. Stone RM, Berg DT, George SL, Dodge RK, Paciucci PA, Schulman P, Lee EJ, Moore JO, Powell BL, Schiffer CA: Granulocyte-macrophage colony-stimulating factor after initial chemotherapy for elderly patients with primary acute myelogenous leukemia. Cancer and Leukemia Group B. New Engl J Med 1995, 332(25): $1671-1677$

4. Godwin JE, Kopecky KJ, Head DR, Willman CL, Leith CP, Hynes HE, Balcerzak SP, Appelbaum FR: A double-blind placebo-controlled trial of granulocyte colony-stimulating factor in elderly patients with previously untreated acute myeloid leukemia: A Southwest Oncology Group Study (903I). Blood 1998, 9 I (10):3607-36 I5

5. Hamblin TJ: Disappointments in treating acute leukemia in the elderly. $N$ Engl J Med 1995, 332(25): 1712-1713

6. Schiffer CA: Hematopoietic growth factors as adjuncts to the treatment of acute myeloid leukemia. Blood 1996, 88(10):3675-3685

7. Jahns-Streubel G, Reuter C, Unterhalt M, Schleyer E, Wormann B, Buchner T, Hiddemann W: Blast cell proliferative activity and sensitivity to GM-CSF in vitro are associated with early re- 
sponse to TAD-9 induction therapy in acute myeloid leukemia. Leukemia I995, 9(I I):1857-I863

8. Karp JE, Burke PJ, Donehower RC: Effects of rhGM-CSF on intracellular ara-C pharmacology in vitro in acute myelocytic leukemia: comparability with drug-induced humoral stimulatory activity. Leukemia 1990, 4(8):553-556

9. Liesveld JL, Keng PC, Rowe JM, DiPersio JF, Abboud CN: Effects of GM-CSF on Ki67 expression and cell cycle traverse in acute myelogenous leukemia specimens and cell lines. Leuk Res 1994, I 8(8):609-616

10. Smith MA, Smith JG, Pallister CJ, Singer CR: Haemopoietic growth factors the cell cycle of acute myeloblastic leukaemia progenitors and sensitivity to cytosine arabinoside. Leuk Lymphoma 1996, 23(5-6):467-472

II. Tanaka M: Recombinant GM-CSF modulates the metabolism of cytosine arabinoside in leukemic cells in bone marrow. Leuk Res 1993, I 7(7):585-592

12. te Boekhorst PA, Lowenberg B, Sonneveld P: Hematopoietic growth factor stimulation and cytarabine cytotoxicity in vitro: effects in untreated and relapsed or primary refractory acute myeloid leukemia cells. Leukemia 1994, 8(9): I480-I 486

13. te Boekhorst PA, Lowenberg B, Vlastuin M, Sonneveld P: Enhanced chemosensitivity of clonogenic blasts from patients with acute myeloid leukemia by G-CSF IL-3 or GM-CSF stimulation. Leukemia 1993, 7(8): I|91-1 I98

14. Bernell P, Kimby E, Hast R: Recombinant human granulocytemacrophage colony-stimulating factor in combination with standard induction chemotherapy in acute myeloid leukemia evolving from myelodysplastic syndromes: a pilot study. Leukemia 1994, 8(1 0): I631-1639

15. Estey E, Thall P, Andreeff M, Beran M, Kantarjian H, O'Brien S, Escudier S, Robertson LE, Koller C, Kornblau S: Use of granulocyte colony-stimulating factor before during and after fludarabine plus cytarabine induction therapy of newly diagnosed acute myelogenous leukemia or myelodysplastic syndromes: comparison with fludarabine plus cytarabine without granulocyte colony-stimulating factor. J Clin Oncol 1994, I2(4):67I-678

16. Hansen PB, Johnsen HE, Jensen L, Gaarsdal E, Simonsen K, Ralfkiaer E: Priming and treatment with molgramostim (rhGM-CSF) in adult high-risk acute myeloid leukemia during induction chemotherapy: a prospective randomized pilot study. Eur J Haematol 1995, 54(5):296-303

17. Buchner T, Hiddemann W, Wormann B, Rottmann R, Maschmeyer G, Ludwig WD, Zuhlsdorf M, Buntkirchen K, Sander A, Aswald J: The role of GM-CSF in the treatment of acute myeloid leukemia. Leuk Lymphoma 1993, I I (Suppl 2):2 I-24

18. Puntous M, Lacombe F, Dumain P, Marit G, Cony-Makhoul P, Belloc $F$, Boiron JM, Laurent G, Bernard P, Reiffers J: Treatment of relapsed acute myeloid leukemia using GM-CSF before intensive chemotherapy. Leuk Lymphoma 1993, I 2(I-2):95-102

19. Valent P, Sillaber C, Geissler K, Andreeff M, Tafuri A, Vieder L, Schulz G, Lechner K, Bettelheim P: Combination treatment of acute myeloblastic leukemia with rhGM-CSF and standard induction chemotherapy. Cancer Invest 1993, I I (2):229-234

20. Ohno R, Naoe T, Kanamaru A, Yoshida M, Hiraoka A, Kobayashi T, Ueda T, Minami S, Morishima Y, Saito Y: A double-blind controlled study of granulocyte colony-stimulating factor started two days before induction chemotherapy in refractory acute myeloid leukemia. Kohseisho Leukemia Study Group. Blood 1994, 83(8):2086-2092

21. Heil G, Chadid L, Hoelzer D, Seipelt G, Mitrou P, Huber C, Kolbe K, Mertelsmann R, Lindemann A, Frisch J: GM-CSF in a double-blind randomized placebo controlled trial in therapy of adult patients with de novo acute myeloid leukemia (AML). Leukemia 1995, 9(I):3-9

22. Witz F, Sadoun A, Perrin MC, Berthou C, Briere J, Cahn JY, Lioure B, Witz B, Francois S, Desablens B, Pignon B, Le Prise PY, Audhuy B, Caillot D, Casassus P, Delain M, Christian B, Tellier Z, Polin V, Hurteloup $P$, Harousseau JL: A placebo-controlled study of recombinant granulocyte-macrophage colony-stimulating factor administered during and after induction treatment for de novo acute myelogenous leukemia in elderly patients. Blood 1998, 9 I(8):2722-2730

23. Lowenberg B, Boogaerts MA, Daenen SM, Verhoef GE, Hagenbeek A, Vellenga E, Ossenkoppele GJ, Huijgens PC, Verdonck LF, van der Lelie J, Wielenga JJ, Schouten HC, Gmur J, Gratwohl A, Hess U, Fey MF, van Putten WL: Value of different modalities of granulocytemacrophage colony-stimulating factor applied during or after induction therapy of acute myeloid leukemia. J Clin Oncol I 997, I 5( I 2):3496-3506

24. Hansen PB, Johnsen HE, Lund JO, Hansen MS, Hansen NE: Unexpected hepatotoxicity after priming and treatment with molgramostim (rhGM-CSF) in acute myeloid leukemia during induction chemotherapy. Am J Hematol I 995, 48(I):48-5 I

25. Wiley JS, Jamieson GP, Cebon JS, Woodruff RK, McKendrick JJ, Szer J, Gibson J, Sheridan WP, Biggs JC, Rallings MC: Cytokine priming of acute myeloid leukemia may produce a pulmonary syndrome when associated with a rapid increase in peripheral blood myeloblasts [letter]. Blood I993, 82(I I):35I I-35 I2

26. Estey EH: Use of colony-stimulating factors in the treatment of acute myeloid leukemia. Blood 1994, 83(8):2015-2019

27. Burke PJ, Karp JE, Vaughan WP, Sanford PL: Recruitment of quiescent tumor by humoral stimulatory activity: requirements for successful chemotherapy. Blood Cells 1982, 8(3):519-533

28. Geller RB, Burke PJ, Karp JE, Humphrey RL, Braine HG, Tucker RW, Fox MG, Zahurak M, Morrell L, Hall KL: A two-step timed sequential treatment for acute myelocytic leukemia. Blood 1989, 74(5): $1499-1506$

29. Arlin ZA, Kempin SJ, Mertelsmann R, Gee TS, Clarkson B: Patients with secondary acute myelocytic leukemia (AML) receiving "timed" sequential chemotherapy [letter]. J Clin Oncol 1983, I(8):5। 3

30. Archimbaud E, Leblond V, Fenaux P, Dombret H, Cordonnier C, Dreyfus F, Cony-Makhoul P, Tilly H, Troussard X, Auzanneau G, Thomas $X$, Ffrench $M$, Marie JP: Timed sequential chemotherapy for advanced acute myeloid leukemia. Hematol Cell Therapy 1996, 38(2):161-167

31. Kalaycio M: Inpatient managment of acute leukemia. Cleveland Clinic Journal of Medicine 1997, 64(7):385-389

32. Archimbaud E, Leblond V, Michallet M, Cordonnier C, Fenaux P, Travade $P$, Dreyfus $F$, Jaubert J, Devaux $Y$, Fiere $D$ : Intensive sequential chemotherapy with mitoxantrone and continuous infusion etoposide and cytarabine for previously treated acute myelogenous leukemia. Blood I991, 77(9): 1894-1900

33. Tafuri A, Andreeff M: Cell kinetic modulation of hematological malignancies by cytokines: Recruitment therapy to overcome cytokinetic resistance. In: Hematopoietic growth factors in clinical applications (Edited by: Mertelsmann R Herrmann F) New York Marcel Dekker Inc. 1990, 38I-399

34. Rowe JM, Neuberg D, Friedenberg W, et al: A phase III study of daunorubicin vs idarubicin vs mitoxantrone for older adult patients ( $>55$ yrs) with acute myelogenous leukemia (AML): a study of the Eastern Cooperative Oncology Group (E3993). Blood 1998, 92(Suppl):Abs I284

35. Reece DE, Elmongy MB, Barnett MJ, Klingemann HG, Shepherd JD, Phillips GL: Chemotherapy with high-dose cytosine arabinoside and mitoxantrone for poor-prognosis myeloid leukemias. Cancer Invest 1993, I I (5):509-5 I6

36. Hiddemann W, Aul C, Maschmeyer G, Schonrock-Nabulsi R, Ludwig WD, Bartholomaus A, Bettelheim P, Becker K, Balleisen L, Lathan B: High-dose versus intermediate dose cytosine arabinoside combined with mitoxantrone for the treatment of relapsed and refractory acute myeloid leukemia: results of an age adjusted randomized comparison. Leuk Lymphoma 1993, 10:133137

37. Vogler WR, Velez-Garcia E, Weiner RS, Flaum MA, Bartolucci AA, Omura GA, Gerber MC, Banks PL: A phase III trial comparing idarubicin and daunorubicin in combination with cytarabine in acute myelogenous leukemia: a Southeastern Cancer Study Group Study. I Clin Oncol I 992, I 0(7): I 103- I I I I

38. Kern W, Schleyer E, Unterhalt M, Wormann B, Buchner T, Hiddemann W: High antileukemic activity of sequential high dose cytosine arabinoside and mitoxantrone in patients with refractory acute leukemias. Results of a clinical phase II study. Cancer 1997, 79(I):59-68

39. Schiller G, Emmanoulides C, lastrebner M, Lee M, Naeim F: Highdose cytarabine and recombinant human granulocyte colony-stimulating factor for the treatment of resistant acute myelogenous leukemia. Leuk Lymphoma 1996, 20(5-6):427-434

40. Archimbaud E, Thomas X, Leblond V, Michallet M, Fenaux P, Cordonnier $C$, Dreyfus $F$, Troussard $X$, Jaubert J, Travade $P$ : Timed sequential chemotherapy for previously treated patients with acute 
myeloid leukemia: long-term follow-up of the etoposide mitoxantrone and cytarabine-86 trial. J Clin Oncol 1995, I3(1): I I18

4I. Thomas X, Fenaux P, Dombret H, Delair S, Dreyfus F, Tilly H, Vekhoff A, Cony-Makhoul P, Leblond V, Troussard X, Cordonnier C, de Revel T, Simon M, Nicolini F, Stoppa AM, Janvier M, Bordessoule D, Rousselot P, Ffrench M, Marie JP, Archimbaud E: Granulocyte-macrophage colony-stimulating factor (GM-CSF) to increase efficacy of intensive sequential chemotherapy with etoposide mitoxantrone and cytarabine (EMA) in previously treated acute myeloid leukemia: a multicenter randomized placebo-controlled trial (EMA9I Trial). Leukemia I999, 13:1214-1220

42. Hoyle CF, de Bastos M, Wheatley K, Sherrington PD, Fischer PJ, Rees JK, Gray R, Hayhoe FG: AML associated with previous cytotoxic therapy MDS or myeloproliferative disorders: results from the MRC's 9th AML trial. Br J Haematol 1989, 72(I):45-53

43. Kantarjian HM, Estey EH, Keating MJ: Treatment of therapy-related leukemia and myelodysplastic syndrome. Hematol Oncol Clin Nor Am 1993, 7(I):81-108

44. Loffler H, Schmitz N, Gassmann W: Intensive chemotherapy and bone marrow transplantation for myelodysplastic syndromes. Hematol Oncol Clin Nor Am 1992, 6(3):619-631

45. Mitus AJ, Miller KB, Schenkein DP, Ryan HF, Parsons SK, Wheeler C, Antin JH: Improved survival for patients acute myelogenous leukemia. J Clin Oncol 1995, 13(3):560-569

46. Woods WG, Kobrinsky N, Buckley JD, Lee JW, Sanders J, Neudorf S, Gold S, Barnard DR, DeSwarte J, Dusenbery K, Kalousek D, Arthur DC, Lange BJ: Timed-sequential induction therapy improves postremission outcome in acute myeloid leukemia: a report from the Children's Cancer Group. Blood 1996, 87(12):4979-89

47. Bennett JM, Catovsky D, Daniel MT, Flandrin G, Galton DAG, Gralnick HR, Sultan C: Proposed revised criteria for the classification of acute myeloid leukemia. Ann Intern Med 1985, 1 03:626

\section{Pre-publication history}

The pre-publication history for this paper can be accessed here:

http://www.biomedcentral.com/1471-2407/2/12/prepub

\begin{tabular}{|}
\hline Publish with BioMed Central and every \\
scientist can read your work free of charge \\
"BioMedcentral will be the most significant development for \\
disseminating the results of biomedical research in our lifetime." \\
Paul Nurse, Director-General, Imperial Cancer Research Fund \\
Publish with BMC and your research papers will be: \\
• available free of charge to the entire biomedical community \\
• peer reviewed and published immediately upon acceptance \\
- cited in PubMed and archived on PubMed Central \\
• yours - you keep the copyright \\
Submit your manuscript here: \\
http://www.biomedcentral.com/manuscript/
\end{tabular}

